\title{
Thyroid-Binding Globulin Excess
}

National Cancer Institute

\section{Source}

National Cancer Institute. Thyroid-Binding Globulin Excess. NCI Thesaurus. Code C131023.

Supranormal concentration of thyroid-binding globulin. 